\title{
Exploring the direct and indirect effects of emotional intelligence and frequency of customer contact on organisational citizenship behaviours among hotel employees in Mexico
}

\begin{abstract}
In the hotel industry, organisational effectiveness and service quality are highly dependent on front-of-house employees' positive interactions with customers, and their willingness to engage in organisational citizenship behaviours (OCB). Various studies have identified the ability of employees to manage their own emotions and those of others as a key means of understanding how and why employees engage in OCB. The present study seeks to shed light on how the underlying mechanisms of emotional intelligence (EI) and the nature of job role through the frequency of interactions with customers could be of benefit to service orientated organisations. Empirical evidence was drawn from a sample of 179 front-of-house employees from a 4-star Mexican hotel chain. A series of multiple hierarchical regressions revealed that when employees experience high levels of customer contact and engage in high levels of emotion regulation, this can have a detrimental effect on their $O C B$. The findings underscore the importance of the role of work and job context in influencing the EI and OCB relationship.
\end{abstract}

Keywords: Emotional Intelligence, OCB, Hotels, Service Sector 
Angeli Santos

Division of Psychiatry and Applied Psychology, The University of Nottingham, Wollaton Road

Nottingham, NG8 1BB, United Kingdom

Email: angeli.santos@nottingham.ac.uk

Angeli Santos is an Associate Professor in Applied Psychology and Course Director of the MSc Work and Organisational Psychology at the Division of Psychiatry and Applied Psychology, School of Medicine, University of Nottingham, UK. She completed her Undergraduate degree in Psychology at the Ateneo de Manila University (Philippines) in 1999, and her MSc in Occupational Health Psychology and PhD in Applied Psychology degrees at the University of Nottingham (UK) in 2000 and 2004, respectively. Prior to her present post, she was seconded to the Malaysia Campus in 2008 for a period of seven years where she served as head of department and associate dean for teaching and learning.

Michael Mustafa

Nottingham University Business School, The University of Nottingham Malaysia Campus, Semenyih, Malaysia

Email: michael.mustafa@nottingham.edu.my

Michael Mustafa studied Economics at the Australian National University, specialising in international and development economics, and received a Master's in Management from the National Graduate School of Management. His current research interests include internationalisation strategies of family firms, transnational entrepreneurship and corporate entrepreneurship.

Ana Ayala Cantu,

Division of Psychiatry and Applied Psychology, The University of Nottingham, Wollaton Road

Nottingham, NG8 1BB, United Kingdom

E-mail: anayalacantu@gmail.com

Ana completed MSc in Work and Organisational Psychology at the University of Nottingham in 2016. 


\section{Exploring the direct and indirect effects of emotional intelligence and frequency of customer contact on organisational citizenship behaviours among hotel employees in Mexico}

\section{Introduction}

The past 40 years have seen a considerable shift in employment trends away from the manufacturing sector to the service sector. Such changes have meant that employees are now finding themselves having to engage in frequent interactions with customers. In the hotel industry, organisational effectiveness and service quality are highly dependent on front-ofhouse employees' positive interactions with customers (Jung and Yoon, 2012; Ramachandran et al., 2011). Presented with the challenge of having to satisfy customer demands and expectations, hotels are increasingly requiring their front-of-house employees to engage in organisational citizenship behaviours (OCB) (Ma and Qu, 2011; Organ, 1998). OCB consist of individual discretionary behaviours that are over and above an individual's job description (Ma et al., 2013), and are considered to be important determinants of organisational effectiveness (Bateman and Organ, 1983; Podsakoff et al., 2009). Given the importance of OCB to organisational functioning, it is important to understand the mechanisms through which such citizenship behaviours emerge (Dai et al., 2018).

Organisations can be viewed as social entities comprised of individuals who regularly engage in emotionally laden exchanges with their colleagues and customers (Carmeli and Josman, 2006). As a result, organisations have become increasingly dependent on their employees' ability to understand and manage their own emotions as well as those around them. Emotional intelligence (EI) has been described as a dispositional factor that consists of one's ability to engage in sophisticated information processing about one's own emotions and those of others, and the ability to use this information to guide thinking and behaviour (Devonish, 
2016; Mayer et al., 2008). Hence, apart from cognitive intelligence, emotional intelligence (EI) has emerged as a key concept in understanding how employees and organisations function (Druskat and Wolff, 2001; Spector and Fox, 2002).

Previous research has established a strong relationship between EI and OCB (see Miao et al., 2016; Turnipseed, 2003; Turnipseed and Vandewaa, 2012). However, many questions remain as to how exactly EI influences OCB (Miao, Humphrey and Qian, 2016). Specifically, little is known of how specific role requirements may influence the EI-OCB relationship (Bozionelos and Singh, 2017; Jung and Yoon, 2012; Santos et al., 2015). For instance, Turnipseed (2016) found that employees' locus of control strengthened the EI-OCB relationship, while Jung and Yoon (2012) demonstrated that the EI-OCB relationship was contingent upon certain job roles. The role of employee interactions with customers in the hotel industry, however, have been largely overlooked. This is surprising, given that various scholars have acknowledged that service work requires extensive customer interactions. Secondly, in service-orientated organisations like hotels, front-of-house employees are critical service providers (Jung and Yoon, 2012). Hence, in these contexts, EI and OCB are of critical importance in achieving organisational effectiveness. Nevertheless, studies of hotel employees' EI and OCB remain limited (Ramachandran et al., 2011).

In addressing the above gaps in the literature, this particular study examines whether front-of-house employees' frequency of customer contact moderates the relationship between their EI and OCB. Drawing on trait activation theory (Tett and Gutterman, 2000), we postulate that front-of-house employees are more likely to employ their EI abilities and display OCB under conditions of high frequency of contact with customers, as such situations provide them with the opportunity to engage in discretionary behaviours. We test our hypothesis using a sample of 179 front-of-house hotel employees from a 4-star Mexican hotel chain. 
The present study aims to shed light on the underlying mechanisms of EI that could be of benefit to service orientated organisations. In examining the frequency of contact with customers as a moderator in the EI-OCB relationship, our study addresses the growing call in the literature to take into account the role of job context on EI and OCB (Miao et al., 2016). Moreover, by focusing on the experience of Mexican hotel employees, we hope to provide much needed empirical evidence of importance of the EI-OCB relationship in the hotel industry.

\section{Theoretical Background}

\subsection{Organisational Citizenship Behaviour in the Service Industry}

Service orientated employees play critical roles in enhancing and promoting customer satisfaction, loyalty, and in turn, their organisation's image and performance (Hartel et al., 2008). Service orientated employees can make a positive contribution to their organisation by engaging in non-formalized tasks (Borman and Motowidlo, 1997). Such non-formal tasks often occur beyond an employee's formal role requirements and are typically referred to as extrarole behaviours (Van Dyne and LePine, 1998). Various studies have demonstrated the centrality of such organisational citizenship behaviours (Organ, 1998) to organisational functioning (Kumari and Thapliyal, 2017; Podsakoff et al., 2009).

According to Organ, OCB are "behaviour(s) of a discretionary nature that are not part of the employee's formal role requirements, but nevertheless promote the effective functioning of the organization" (1998, p. 4). Such behaviour is typically not recognized by organisational reward systems (Organ et al., 2006). Karambayya (1989) further suggested the OCB highlight the extent of interdependence among employees of an organisation, and hence, closely mirror the life of the organisation. McNelly and Meglino (1994) conceptualized OCB as comprising two dimensions. The first dimension refers to altruistic behaviours intended to help others in the organisation (OCB-P). Such altruistic behaviours typically manifest themselves in the form of helping co-workers finish their work, orienting newcomers to the organisation or addressing 
customers' unique wants and expectations. The second dimension refers to general conscientiousness or compliance-related behaviours. These typically manifest themselves in behaviours such as being creative, not spending time in idle conversation, not taking undeserved breaks, etc., and are intended to help or benefit the organisation (OCB-O) (Spector and Fox, 2002). Podsakoff et al. (2000) suggested that general conscientiousness or compliance-related behaviours reflect an employee's internalization and acceptance of organisational rules, regulations and procedures. Hence, such behaviours could result in conscious obedience by employees even in the absence of monitoring.

Addressing specific customer wants, needs and expectations are a central feature of hotel employees' roles (Albrecht and Zemke, 1985). In particular, front-of-house employees are often required to adapt their work behaviour in order to deal with individualized customer needs (Stamper and Van Dyne, 2003). Prior research suggests that compared to the manufacturing industry, OCB are more important to service orientated industries because of the frequent, and often intense, nature of face-to-face contact with customers (Bartel, 2004; Jung and Yoon, 2012). OCB has been related to a number of critical outcomes such as improved employee-customer interactions, improved "service climate" (Armario et al., 2004), enhanced service quality and customer loyalty (Castero et al., 2004; Suh and Yoon, 2003) and positive evaluations of customer service (Bienstock et al., 2003). Given its significance to organisational effectiveness (Weinberger, 2003), various studies have sought to understand how OCB occur in employees (see Jung and Yoon, 2012; Nadiri and Tanova, 2010; Chiu et al., 2015).

There has been a growing recognition among scholars of the importance of emotional intelligence (EI) (Mayer and Salovey, 1997) as a predictor of employee OCB (Miao et al., 2016; Ramachandran et al., 2011; Turnipseed, 2017; Turnipseed and Vandewaa, 2012). EI is particularly relevant for front-of-house hotel employees as the very nature of their roles require 
emotionally based interactions with customers, thus requiring them to understand and manage not only their own emotions but those of the customers (Carmeli and Josman, 2006; Kearney et al., 2017).

\subsection{Emotional Intelligence and OCB among Service Employees}

Emotions are quintessential to human experience (Ashforth and Humphrey, 1995) as they influence not only one's thoughts but also their actions. Emotional intelligence (EI) is considered as an important predictor of individual outcomes in the workplace (Miao et al., 2016; Van Rooy and Viswesvaran, 2004; Walter et al., 2011). Theoretical approaches to EI have traditionally developed along two paths (Ashkansay and Duas, 2005); namely the abilitybased and mixed models. Based largely on Goleman's (1995) seminal work on EI, the mixed model approaches represent a mixture of three key constructs: personality traits, personal competencies (e.g., optimism, self-esteem), and perceived emotional ability. In contrast, ability-based approaches conceptualize EI as a standard form of intelligence (Brackett et al., 2011) comprising mental traits or abilities which can be assessed. A recent meta-analyses has shown the ability-based approach to be both conceptually and empirically distinct from the mixed model approach (Miao et al., 2016). This particular study adopts the ability-based approach to EI as it provides a useful framework for the identification of specific skills needed to understand and experience emotions in the workplace (Koman and Wolff, 2008; Mayer et al., 2008), which could, in turn, guide individual behaviour and thinking in ways that can improve organisational performance.

According to the ability based approach, EI can be defined as "the ability to monitor one's own and others feelings and emotions, to discriminate among them and to use this information to guide ones thinking" (Mayer et al., 1999). EI essentially focuses on the recognition, appraisal, expression, and management of one's own emotions and those of others (Carmeli and Josman, 2006). The above definition proposes that EI is a construct 
composed of four dimensions: self-emotion appraisal, involves being able to comprehend one's own internal emotions; others' emotion appraisal refers to the ability to comprehend others' emotions; use of emotion concerns the capacity to apply emotions to performance and action; and regulation of emotion pertains to the skills utilized to regulate one's emotions (Wong and Law, 2002). Employees with increased levels of EI are more likely to be high achievers in their roles and are thus expected to contribute to their organisation's effectiveness (Carmeli and Josman, 2006; Turnipseed and Vandewaa, 2012).

The ability to use, understand, perceive and manage emotions can influence employee performance. Studies have shown the positive effects of EI on both in-role and extrarole performance (Antonakis, 2004; Lee and Ok, 2012; Cote and Miners, 2006; Hui-Hua and Schutte, 2015; Scott-Halsell et al., 2008), suggesting that employees with high EI have a competitive advantage in the workplace. EI is considered particularly influential in the encouragement of voluntary behaviours such as OCB which are influenced by emotional characteristics (Bozionelos and Singh, 2017; Organ and Konovsky, 1989; Wong and Law, 2002). Erez and Isen (2002) suggested that the very nature of OCB is linked to interpersonal interactions, and thus employees with higher EI tend to have better relationships with fellow colleagues and customers (Mayer et al., 2008). Employees with high EI are also more likely to engage in altruistic behaviours as they are better able to recognize and understand their coworkers' feelings (Abraham, 1999), and are consequently more likely to assist fellow employees with everyday routines by taking on extra work (Carmeli and Josman 2006; Organ, 1988) and more willing to help new employees adjust to the organisation.

Employees with high EI are also more likely to engage in social interactions with fellow employees and customers and allow them to better select and use information from such interactions to execute behaviours that maximize the probability of goal attainment (Turnipseed and Vandewaa, 2012). Such positive interactions allow employees the opportunity to identify 
organisational and customer related issues, and subsequently engage in behaviours and actions that will serve the interests of fellow colleagues and/or customers. Groves and Vance (2009) and others also suggested that emotionally intelligent employees will be better at using their emotions to facilitate cognitive activities such as problem solving and thinking outside of the box (Turnipseed and Vandewaa, 2012; Turnipseed, 2016). In sum, such behaviours are likely to benefit the organisation and its customers by providing a better quality of service and improving organisational processes.

Turnipseed (2016) further suggested that employees with high EI are more likely to be in-tune with their organisation's goals and behavioural expectations. This is often attributed to the fact that emotionally intelligent employees are more adept at reading environmental and situational cues. Such employees are also likely to be more empathetic towards their organisation (Cohen and Abedallah, 2015). Because of their sensitivity to their environment, employees with high EI may display compliance orientated behaviours, aimed at helping the overall organisation. Additionally, such employees will be more likely to perceive, regulate and utilize their emotions in the workplace (Carmeli and Josman, 2006). Such abilities mean that emotionally intelligent employees are more likely to engage in discretionary citizenship behaviours and actions that will benefit the organisation.

Extensive research has been done on the relationship of EI and OCB (Miao et al., 2016; Miao, Humphrey and Qian, 2017) in a variety of organisational and industrial contexts. The limited number of studies in the hotel industry however have revealed mixed findings regarding the nature of the EI-OCB relationship. For instance, Jung and Yoon (2012) found only two dimensions of EI (self-emotion appraisal and use of emotions) to positively influence OCB, while Ramachandran et al. (2011) found only the use of emotions to predict service employees' OCB. In sum, we suggest that if front-of-house hotel employees are able to understand their own emotions and know when to use them, it could lead to a more positive work environment, 
and altruistic and compliance related behaviours, which thus lead to an increase in OCB. Therefore we propose the following hypothesis:

H1: Emotional intelligence is positively related to front-of-house hotel employees' organisational citizenship behaviour

\subsection{Frequency of Customer Contact as a Moderator in the EI-OCB Relationship}

Various scholars have acknowledged that the validity of EI may be contingent on specific contexts (Khalili, 2017; Miao et al. 2016; Mustafa et al., 2016). Specifically, work contexts and job roles have been identified as containing salient emotion-based cues that are likely to activate certain elements of EI that elicit pro-organisational and pro-social behaviours (Miao et al., 2016; Woods et al., 2017). This particular study proposes that front-of-house hotel employees' frequency of contact with customers as one type of job requirement that may influence the relationship between EI and OCB. Santos et al. (2015) and others suggested that service employees' jobs traditionally require a high level of interpersonal contact with internal and external clients (Kulik et al., 2009; Lee and Ok, 2012). Moreover, the frequency of such interactions has been shown to have a substantial impact on employees' abilities and their use of emotions (Kearney et al., 2017; Mustafa et al., 2016).

Jung and Yoon (2012) showed further evidence that among hotel employees the type of job (eg back of house $(\mathrm{BOH})$ or front-of-house $(\mathrm{FOH}))$ attenuated the relationship between EI and OCB. They reasoned that FOH employees had more frequent contact with customers compared to $\mathrm{BOH}$ employees and thus more opportunities to use their emotions to engage in OCB. We draw on trait-activation theory (Tett and Gutterman, 2000) as a means to explain the nature of the relationship between EI and frequency of customer contact with service employees' OCB. Trait activation theory proposes that certain job requirements, e.g. frequent customer contact, can activate specific trait and emotionally relevant cues. Moreover, the 
activation of such trait and emotionally relevant cues can lead to the expression of specific psychological traits and emotional reactions, therefore stimulating one to behave in a manner that corresponds to contextual clues.

Emotionally intelligent employees are highly social, uniquely attuned to others' emotions, empathetic and sympathetic (Turnipseed, 2016). They are also good at perceiving, expressing and using emotions. Frequent interactions with customers provide front-of-house hotel employees with the opportunity to perceive and better understand the emotional needs of their customers. Such situations provide employees with the necessary motivation to go beyond their formal job requirements to help address customers' emotional and physical needs. Social skills also include the ability to select and use information form an interpersonal context to determine appropriate goal directed behaviour (Beauchamp and Anderson, 2010).

Similarly, having frequent interactions with customers affords emotionally intelligent front-of-house hotel employees the opportunity to quickly acquire relevant information related to emergent issues within the organisation (Elfenbein and MacCann, 2017). Being aware of such issues may motivate employees to engage in altruistic behaviours such as helping fellow colleagues adjust to new working conditions or informally mentoring colleagues to develop their skills, in order to address customer-related issues as a means of improving service quality. Furthermore, frequent customer interactions may lead emotionally intelligent front-of-house hotel employees to become more accustomed to organisational systems and processes (Turnipseed, 2016). Consequently, such employees may be motivated, through their frequent exchanges with both customers and fellow colleagues, to employ creative ways of working around issues in order to improve service quality. Finally, emotionally intelligent front-ofhouse hotel employees are also more likely to be aware of their organisation's goals and expectations (Mayer et al., 1999). Thus, through frequent interactions with customers, frontof-house employees may be more willing to respond appropriately in their use of emotions 
when dealing with customers in order to meet organisational expectations. In sum, we postulate that front-of-house hotel employees with a higher frequency of contact with customers are more likely to exhibit higher levels of EI and OCB, as the demands for emotion management in such situations may be particularly high, as are the opportunities to engage in discretionary behaviours (Johnston and Spector, 2007; Santos et al., 2015). Therefore, we propose the following hypothesis:

H2: Frequency of customer contact will moderate the relationship between front-of-house hotel employees' emotional intelligence and organisational citizenship behaviours

\section{Method}

\subsection{Procedure and Sample}

This study used convenience sampling to select and recruit front-of-house hotel staff. Similar to Ninemeier and Perdue (2007), we defined front-of-house employees as those employees who have regular contacts with guests, while back of house employees were defined as those that have little or no direct contact with guests. In collecting data from front-of-house hotel employees, the authors approached the Human Resource director of a local 4-star hotel chain in Mexico through a personal contact of the one of the authors. The chain, which included 4 hotels, had approximately 450 employees in total. With the help of the hotel's HR director, 210 employees whose roles were considered as part of front-of-house operations were identified. Accordingly, with the assistance of the HR director, 210 survey packages were distributed to the front-of-house personnel with their pay packet. Each survey package included the participant information and consent form and a copy of questionnaire. Employees were given a month to complete the survey package, with HR sending out fortnightly reminders. All completed questionnaires were placed inside the envelopes provide in the survey package, and 
deposited in a secure drop-box at the HR department. A total of 185 questionnaires were received, although, in the end, only 179 of the returned questionnaires were deemed to be suitable for further analyses, resulting in a response rate of $85.2 \%$

$50.3 \%$ of respondents were female, and on average respondents were $35.58(\mathrm{SD}=$ 12.66) years of age. Most respondents were either in front desk roles $(50.2 \%)$ followed by waiters or assistants (21.8\%). $11.8 \%$ of respondents were in the role of concierge or similar and finally $16.2 \%$ were in managerial or supervisory roles. Just over half $(50.3 \%)$ of participants had been with the organisation for less than a year, with $16.2 \%$ for a year and $5.6 \%$ for 3 years. Moreover, when asked about tenure in the hotel industry, $22.9 \%$ had been in the industry for less than a year, $9.5 \%$ for a year, and $6.7 \%$ for 10 years. Regarding the participants' frequency of contact with costumers, $56.4 \%$ always had contact, $11.7 \%$ almost always, $17.3 \%$ sometimes, $12.8 \%$ almost never, and $1.7 \%$ never.

\subsection{Measures}

Emotional Intelligence. Wong and Law's 16 items Emotional Intelligence Scale (WLEIS) was used to assess EI (Wong and Law, 2002). Four items measured each of EIs four dimensions: Self-emotion Appraisal (SEO) ("I have a good understanding of my own emotions"), Others' Emotion Appraisal (OEA) ("I am sensitive to the feelings and emotions of others"), Use of Emotion (UOE) (“I always tell myself I am a competent person") and Regulation of Emotion (ROE) ("I have good control of my own emotions"). All items were rated on a 7-point Likert scale $(1=$ strongly agree, $7=$ strongly disagree $)$. The Cronbach's alpha reported for the scale was 0.91

Organisational Citizenship Behaviour. The 20-item Organisational Citizenship Behaviour Checklist (OCB-C) was used to measure service employees OCB (Fox et al., 2009). The scale consists of asking the respondents to rate how often they have engaged in extra-role behaviours 
directed towards the organisation (OCB-O) and towards individuals within the organisation (OCB-P), as well as altruistic acts that that helped co-workers with personal as opposed to workplace issues. In the present study, the overall scale (OCB-C) and its subscales OCB-O and OCB-P were used. Example items include "Helped a co-worker learn new skills or shared job knowledge" (OCB-O) and "Changed vacation schedule, work days, or shifts to accommodate co-worker's needs" (OCB-P). All responses were are rated on a 5-point Likert scale ( $1=$ never, $5=$ everyday). The reported coefficient alphas for this scale ranged from 0.89 to 0.94 .

\section{Frequency of daily contact with customers}

Front-of-hose employees were asked to rate the frequency of contact or interactions that they had with costumers on a daily basis, ranging from never (0) to always (5). Additionally, we also collected information on participants' background and job characteristics. Regarding respondent's background information, we measured gender as a dichotomous variable $(0=$ Male and $1=$ Female. Age was measured as the respondents age at time of completing the survey and tenure as the number of years working in the hotel. Because the present research collected data on both the predictor and outcome variables from the same respondents at one point in time, the potential for common method variance is possible. In order to test for this possibility, a Harman's one factor test in which all items were loaded into one common factor was conducted prior to conducting correlation and regression analyses. According to Podsakoff et al. (2003), if the total variance for a single factor is less than $50 \%$, common method variance does not affect your data. The total variance accounted for by the data in the present study was $27.9 \%$; therefore, it can be said with some certainty than common method variance was not an issue for the present research.

\section{Results}


Table 1 shows the means, standard deviations, correlations and reliability coefficients of the variables used in this study. Looking at the reliability coefficients all variables show an acceptable Cornbach's $\alpha$ (Field, 2013). Pearson's correlations were employed to investigate intercorrelations between study variables. The intercorrelations indicate that the demographic variables largely failed to correlate with the dimensions of emotional intelligence, with the exception of age and tenure which showed modest correlations with OEA and ROE. Demographic variables also showed modest correlations with OCB-C and OCB-O but not OCB-P. All dimensions of emotional intelligence showed modest to moderate correlations with all types of OCB, and were generally strongest for OCB-O.

\section{Insert Table 1 here}

\subsection{Assessing the impact of emotional intelligence and frequency of contact on OCB}

In order to analyse the direct and indirect effects of emotional intelligence and frequency of contact on $\mathrm{OCB}$, three hierarchical multiple regressions were carried out. Prior to analyses preliminary checks were carried out. First, predictors were examined for multicollinearity. According to Field (2013), predictors in a regression model should not correlate by more than .8. As can be seen in Table 1, none of the predictors reached this level. Second, VIF and tolerance statistics were examined. All VIF statistics for each regression model were in the range of $1-4$, which is well below the cut-off of 10 as recommended by Field (2013), whilst tolerance statistics were all in the region of .3 to .9 which is above the recommended cut-off of .2. Demographic variables of age, gender and tenure were entered into the first step of the regression equation, followed by the four dimensions of emotional intelligence and frequency of contact with customers in the second step, and the interaction terms between the various dimensions of EI and frequency of contact with customers in the third step. Results of the regression analyses can be found in Table 2.

\section{Insert Table 2 here}


As can be seen from Table 2, control variables (age, gender, and tenure) explained $7.7 \%$ of the variance of OCB-C. In the second step, EI and frequency of contact with customers contributed to $17.5 \%$ of the variance. Upon examination of the individual beta weights, it can be seen that frequency of contact with customers $(\beta=.277, \mathrm{p}=.000)$ and OEA $(\beta=.234, \mathrm{p}=$ .005) predicted OCB-C. UOE, SEA and ROE failed to significantly predict OCB-C. In the third step, the interaction between the various dimensions of EI and frequency of contact with customers, contributed to a further $6.3 \%$ of the variance in OCB-C. Specifically, frequency of contact significantly buffered the effects of OEA $(\beta=.495, \mathrm{p}=.001)$ on OCB-C, but a reverse buffering effect for ROE $(\beta=-.324, \mathrm{p}=.036)$ was found. The moderation effects for OEA and ROE are depicted in Figures 1 and 2 respectively. As can be seen from Figure 1, high OEA and high frequency of contact with customers resulted in significantly higher OCB-C than low frequency of contact and high OEA. From Figure 2 however, it can be seen that under conditions of high ROE there is virtually no difference in OCB between high or low levels of frequency of contact with customers, suggesting that when employees experience higher levels of customer contact and engage in high levels of emotion regulation, this has a detrimental effect on organisational citizenship behaviours.

Results of the regression analyses for OCB-O reveal a similar pattern of results. Control variables (age, gender, and tenure) explained $10 \%$ of the variance of OCB-O. EI and frequency of contact with customers contributed to a $16.3 \%$ of the variance, while the interaction between EI and frequency of contact contributed to a further $5.8 \%$ of the variance in OCB-O. In terms of direct effects, only OEA $(\beta=.245, \mathrm{p}=.003)$ and frequency of contact $(\beta=.221, \mathrm{p}=.002)$ significantly predicted OCB-O. Frequency of contact with customers significantly buffered the effects of OEA $(\beta=.457, \mathrm{p}=.002)$ on OCB-O. No other buffering effects were observed. 
For OCB-P, a similar pattern of results was also observed. Control variables however failed to significantly predict OCB-P, contributing to only $2 \%$ of the variance. In terms of direct effects, EI and frequency of contact contributed to $19.5 \%$ of the variance, with only OEA $(\beta=.243, \mathrm{p}=.004)$ and frequency of contact $(\beta=.295, \mathrm{p}=.000)$ significantly predicting OCB-P. Interaction effects contributed to a further $4.6 \%$ of the variance in OCB-P, with frequency of contact significantly buffering the effects of OEA $(\beta=.396, p=.010)$ on OCB-P. In summary, hypothesis 1, which predicted that EI would have a direct effect on OCB was partially supported. Hypothesis 2, which predicted that frequency of contact with customers/clients would yield a buffering effect, was partially supported, although both buffering and reverse buffering effects were observed. Frequency of contact however was also found to have a direct effect on all forms of OCB.

\section{Discussion}

This study sought to examine the relationship between the emotional intelligence of front-of-house hotel employees and their OCB. Drawing on trait-congruence theory, frequency of contact with customers was proposed as a potential moderator in this relationship. Multiple hierarchical regression analyses yielded somewhat unexpected, but nonetheless interesting results, which make for a timely, if not valuable contribution to the existing .

Broadly, the study addresses the call in the literature to understand the relationship between EI and OCB (Miao et al., 2016; Turnipseed, 2016). Firstly, the finding that only Others' Emotion Appraisal (OEA) was a significant predictor of OCB directed toward the organisation (OCB-O) and towards individuals within the organisation (OCB-P), contradicts earlier findings by Jung and Yoon (2012) and Ramachandran et al. (2011) who failed to find any significant relationships between OEA and OCB among employees in the hotel industry. By doing so, our findings support those that have found contradictory results regarding the relationship between the various dimensions of EI and OCB (Miao et al., 2016; Turnipseed and 
Vandewaa, 2012). We argue that our findings can at least, in part, be explained by the unique nature of front-of-house hotel employees' roles.

Being sensitive to the feelings and moods of customers represents an important element of front-of-house hotel employees work. The emotional states of customers often convey rich information which requires employees to accurately appraise their emotions and respond with the appropriate behaviours, if they are to satisfy the needs and expectations customers. Consequently, front-of-house hotel employees high in EI are more likely to be sensitive to, and understanding of, slight variations in customers' emotions, such as sadness, happiness, grief etc. (Mayer et al., 2000; Salovey and Grewal, 2005). Emotionally savvy employees are more able recognize and accurately appraise customers' feelings and moods, and are thus more adept at harnessing EI to maintain positive emotions and to regulate their negative moods (Spector and Fox, 2002). This may allow them to experience higher job satisfaction and positive affect which can encourage them to go out their way to help solve issues customers may have, and in so doing, uphold expectations of customer service and customer satisfaction. Such findings broadly support prior studies which suggested that EI may exert an influence on organisations through its link with OCB (Turnipseed and Vandewaa, 2012; Vandewaa and Turnipseed, 2012).

Secondly, our study adds to the existing literature by deepening our understanding of the mechanisms through which EI influences OCB (Miao et al., 2016). Specifically, drawing on trait activation theory we examined how front-of-house hotel employees' frequency of contact with customers/clients moderates the relationship between EI and OCB. In so doing, we demonstrate how the job requirements of front-of-house hotel employees contain traitrelevant cues that may trigger their expression or use of EI, thereby prompting them to attend to these cues, which in turn, promote OCB. Our findings showed that frequency of contact with customers buffered the relationship between OEA and all forms of OCB (C, O and P), such 
that high frequency of contact resulted in significantly higher OCB. Unexpectedly though, frequency of contact with customers had a reverse buffering effect on the relationship between regulation of emotions (ROE) and OCB-C, in that under conditions of high ROE, high frequency of contact resulted in a decrease in OCB.

Through frequent contact with customers, emotionally intelligent employees become well positioned to understand their needs and to collect unique information related to emergent issues within the organisation. This can encourage emotionally intelligent front-ofhouse hotel employees to go beyond their formal job requirements and find unique ways to solve customer related issues and to improve organisational functioning so that customer needs and expectations are met. However, frequent contact with customers on a daily basis can also present front-of-house hotel employees with significant challenges, especially with respect to the skills needed to regulate their emotions which could, in turn, affect their willingness and ability to engage in OCB.

Frequent contact with customers largely involves intense face-to-face interactions which can be emotionally demanding. In organisational settings like hotels, front-of-house employees' interactions with customers may be largely guided by display rules which require them to regulate their feelings or expressions towards customers to accomplish specific objectives (Ashforth and Humphrey, 1995). Accordingly, regulating one's emotions may be akin to the concept of surface acting (SA), which refers to the change of emotional expression without changing the inner emotional state in order to meet organisationally required emotions (Hochschild, 1983). Such efforts require front-of-house employees to have the necessary abilities and skills to regulate emotions which are not natural. Such a requirement can be a particularly time consuming and draining activity for front-of-house hotel employees, as they may not only have to attend to customers' needs but also day-to-day routine tasks. 
Conservation of resources theory (Hobfoll, 1989) proposes that employees are motivated to build and conserve their resources at work in order to minimise the extent to which they expend resources in regulating their emotions. Hence, in situations of high frequency of contact with customers, emotionally intelligent front-of-house hotel employees may have to frequently draw on their own personal resources and energy to suppress their negative emotions and remain polite to moody customers. By doing so, such employees may become less motivated and less likely to acknowledge their customers' concerns or help them with their problems voluntarily. Additionally, such employees who experience frequent contact with customers, may use their ability to regulate their own emotions for malevolent purposes. For instance, in order to avoid personal stress when dealing with customers, front-of-house hotel employees may use their ability to regulate their own emotions to manipulate fellow coworkers or to off-load demanding tasks to them. Thus, they may be more willing to engage in counter-productive work behaviours, in order to conserve their own resources and to avoid personal stress and strain. This suggests that the specific job context of front-of-house employees can dictate the extent to which they employ their EI abilities and engage in OCB.

Finally, the study makes an empirical contribution to the existing literature examining emotions and OCB among employees in the hotel industry (Jung and Yoon, 2012; Ramachandran et al., 2011). Hotel employee roles often involve intense interpersonal interactions with both customers and co-workers. Additionally, many roles in the hotel industry may provide significant autonomy and latitude to engage in discretionary actions in order to appease customers (Ma et al., 2013). However, despite the uniqueness of their roles, there remains little empirical evidence of whether their interactions with customers influence their use of emotions and/or other pro-organisational behaviours (Jung and Yoon, 2012). By examining how the frequency of hotel employees contact with customers influences the 
relationship between EI and OCB, our study goes some way in addressing this gap in our knowledge and in the literature.

Several practical and managerial implications emerge from our findings. Firstly, organisations may need to realize that their front-of-house hotel employees interactions with customers are essential in successfully achieving their organisational goals. Consequently, for employees to perform successfully in such roles and make a positive contribution to their organisation's effectiveness, they not only need to be able to manage their own emotions, but also those of others. In line with Jung and Yoon (2012), our findings reiterate the importance of employees' EI as an important factor in the management of human resources in the hotel industry. Collectively, our findings also suggest that it may be important to provide front-ofhouse hotel employees with additional training that focuses specifically on the development of their EI abilities in order to be better able to manage their emotions in the workplace (Ozer and Benet-Martínez, 2005).

Secondly, organisations need to recognize that while emotional intelligence is desirable and essential for their line of work, EI does not only need to be cultivated but managed effectively. Karatepe et al. (2009) and others have pointed out that hotel work can be particularly stressful, have long hours, and be both emotionally and physically demanding (Jung and Yoon, 2012). Such factors may make it difficult for employees to constantly manage their emotions. Moreover, such poor working conditions may also encourage service staff to engage in counter-productive work behaviours (Suliman and Al-Shaik, 2007) or use their EI abilities to manipulate the emotions of others (Austin, Farrelly, Black and Moore, 2007). Therefore, allowing greater "down-time" or arranging regular job rotations within the organisation may be some methods through which management can help front-line service employees overcome the emotional demands of the role and reduce its negative impact. Finally, given the importance of EI in promoting extra-role and pro-organisational and pro-social 
behaviours, we urge organisations to take greater care in how they select their front-line employees. In addition to aptitude testing, for example, service orientated organisations may also wish to assess prospective employees' emotional intelligence.

\section{Limitations and Directions for Future Research}

Like any study, our study is not without its limitations. Firstly, our study relied on selfreport data from a single source. Podsakoff et al., (2003), argued that such approaches may lead to inflated relationships among the variables thus leading to common method variance (CMV) and biasness in our findings. However, we conducted the post-hoc Harman's one factor test, which revealed a result of only $29 \%$. This suggests that common method variance is not a issue in this particular study. Nevertheless, recent meta-analytic findings by Miao, Humphrey and Qian (2016) showed stark differences in the relationship between EI and OCB based on source of the measure (eg self-report or peer/supervisor reported). Therefore, we urge future researchers to consider incorporating both self-report and peer/supervisor report measures of OCB in future research.

Secondly, findings from this particular study were based on the experiences of respondents from one 4 star hotel chain in Mexico, hence the generalizabilityof our findings to hotels of other classes in the industry may be limited. Hotels can vary significantly between levels with regards to service expectations and quality depending on their star rating (Narangajavana and $\mathrm{Hu}, 2008$ ). Such variations are likely to impact employees' frequency of interactions with customers as well as opportunities to engage in OCB. Therefore we urge future research to consider comparing different hotel star ratings on employee EI and proorganisational behaviours.

Thirdly, our study is limited by its cross-sectional design, which makes it difficult to draw inferences about the causal nature of the relationships examined (Giardini and Frese, 2006). Specifically, it does not necessarily hold true that employees' EI and OCB will remain 
stable over time. In fact, employees may regulate their emotions to excel at work and in life, and perform empathetic prosocial behaviours (Miao et al., 2016). Moreover, employees are likely to learn from their interpersonal interactions on a daily basis. Such learning can lead to better management of their own and others' emotions. Therefore, we suggest that future research consider adopting longitudinal approaches to examine how employees' EI fluctuates over time and how such fluctuations can influence their extra-role behaviours.

Finally, we acknowledge that the model presented in this study may be incomplete. In this particular study, we only focused on frequency of contact with customers as a possible moderator in the relationship between EI and OCB. However, it is also plausible that the way in which employees manage their emotions with customers' might be different to the way they manage their emotions with fellow colleagues. Hence, this might affect their OCB differently. Consequently, we suggest that future research also look at frequency of contact with coworkers as well. While interpersonal interactions are an important element in shaping an employee's EI and decision to engage in OCB (Lopes et al., 2003), we do acknowledge that additional contextual and job-related factors can also affect an employee's decision. Specifically, we suggest that future research may wish to consider factors such as job autonomy, age and tenure as possible moderators in the EI and OCB relationship.

Future research might also wish to consider the role of organisational support provided to employees (Eisenberger and Stinglhamber, 2011). Moorman, Blakely and Niehoff (1998) showed employees' perceptions of organisational support as a powerful motivator in their decision to engage in OCB. Employees who feel that their organisation is looking after their interests, are more likely to help fellow colleagues and comply with organisational requirements. Also, such employees are more likely to have positive emotional attachments with their organisation, senior management, as well as fellow employees, as they may feel that they are treated with empathy. 


\section{References}

Abraham, R. (1999) 'Emotional intelligence in organizations: A conceptualization', Genetic,

Social, and General Psychology Monographs, Vol. 125, No. 2, pp.209-224.

Albrecht, K. and Zemke, R. (1985) 'Service America!', Dow Jones-Irwin.

Antonakis, J. (2004) 'On why “emotional intelligence” will not predict leadership

effectiveness beyond IQ or the "big five": An extension and rejoinder', Organizational

Analysis, Vol. 12, No. 2, pp.171-182.

Armario, E.M., Castro, C.B., Ruiz, D.M. (2004) 'The influence of employee organizational citizenship behavior on customer loyalty', International Journal of Service Industry

Management, Vol.15, No. 1, pp. 27-53.

Ashforth, B.E. and Humphrey, R.H. (1995) 'Emotion in the workplace: A reappraisal', Human Relations, Vol. 48, No. 2, pp.97-125.

Ashkanasy, N. M. and Daus, C. S. (2005) 'Rumors of the death of emotional intelligence in organizational behavior are vastly exaggerated', Journal of Organizational Behavior, Vol. 26, pp. 441-452.

Austin, E.J., Farrelly, D., Black, C. and Moore, H. (2007) 'Emotional intelligence, Machiavellianism and emotional manipulation: Does EI have a dark side?', Personality and Individual differences, Vol. 43, No. 1, pp.179-189.

Bartel, A.P. (2004) 'Human resource management and organizational performance: Evidence from retail banking', Industrial \& Labour Review, Vol. 57, No 2, pp.181-203.

Bateman, T.S. and Organ, D.W. (1983) 'Job satisfaction and the good soldier: The relationship between affect and employee "citizenship", Academy of management Journal, Vol. 26 No. 4, pp.587-595. 
Beauchamp, M.H. and Anderson, M. (2010) 'SOCIAL: an integrative framework for the development of social skills', Psychological Bulletin, Vol. 136, No. 1, pp.39.

Bienstock, C.C., DeMoranville, C.W. and Smith, R.K. (2003) 'Organizational citizenship behavior and service quality', Journal of Services Marketing, Vol. 17, No. 4, pp.357-378. Borman, W.C. and Motowidlo, S.J. (1997) 'Task performance and contextual performance: The meaning for personnel selection research', Human Performance, Vol. 10, No. 2, pp.99109.

Brackett, M.A., Rivers, S.E. and Salovey, P. (2011) 'Emotional intelligence: Implications for personal, social, academic, and workplace success', Social and Personality Psychology Compass, Vol. 5, No.1, pp.88-103.

Bozionelos, N. and Singh, S. K. (2017) 'The relationship of emotional intelligence with task and contextual performance: More than it meets the linear eye', Personality and Individual Differences, Vol. 116, pp. 206-211.

Carmeli, A. and Josman, Z. E (2006) 'The relationship among emotional intelligence, task performance, and organizational citizenship behaviors', Human Performance, Vol. 19, pp. 403-419.

Castro, C., Armario, M. E. and Ruiz, M. D. (2004) 'The influence of employee organizational citizenship behavior on customer loyalty', International Journal of Service Industry Management, Vol. 15, No. 1, pp.27-53.

Chiu, S.F., Lin, S.T. and Han, T.S. (2015) 'Employment status and employee service-oriented organizational citizenship behaviour: The mediating roles of internal mobility opportunity and job insecurity', Career Development International, Vol. 20, No. 2, pp.133-146. 
Cohen, A. and Abedallah, M. (2015) 'The mediating role of burnout on the relationship of emotional intelligence and self-efficacy with OCB and performance', Management Research Review, Vol. 38, No. 1, pp.2-28.

Cote, S. and Miners, C.T. (2006) 'Emotional intelligence, cognitive intelligence, and job performance', Administrative Science Quarterly, Vol. 51, No. 1, pp.1-28.

Dai, You-De, Yu-Hsiang Hou, Kuan-Yang Chen, and Wen-Long Zhuang. (2018) 'To help or not to help: antecedents of hotel employees' organizational citizenship behavior' International Journal of Contemporary Hospitality Management Devonish, D. (2016) 'Emotional intelligence and job performance: the role of psychological well-being', International Journal of Workplace Health Management, Vol. 9, No. 4, pp. 428442.

Druskat, V.U. and Wolff, S.B. (2001) 'Building the emotional intelligence of groups', Harvard Business Review, Vol. 79, No. 3, pp.80-91.

Elfenbein, H. A. and MacCann, C. (2017) 'A closer look at ability emotional intelligence (EI): What are its component parts, and how do they relate to each other?', Social and Personality Psychology Compass, Vol. 11, No 7.

Eisenberger, R. and Stinglhamber, F. (2011) 'Perceived organizational support: Fostering enthusiastic and productive employees. American Psychological Association. Erez, A. and Isen, A.M. (2002) 'The influence of positive affect on the components of expectancy motivation', Journal of Applied Psychology, Vol. 87, No. 6, pp.1055- 1067 Field, A. (2013) Discovering Statistics Using IBM SPSS Statistics, 4th ed., Sage, London. Fox, S., Spector, P.E., Goh, A., Bruursema, K. and Kessler, S.R. (2009) 'The deviant citizen: Clarifying the measurement of organizational citizenship behavior and its relation to counterproductive work behavior' Loyola University Chicago. 
Giardini, A. and Frese, M. (2006) 'Reducing the negative effects of emotion work in service occupations: emotional competence as a psychological resource', Journal of Occupational Health Psychology, Vol. 11, No. 1, pp.63-75

Groves, K.S. and Vance, C.M. (2009) 'Examining managerial thinking style, EQ, and organizational commitment', Journal of Managerial Issues, Vol. 21, No. 3, pp. 344-366 pp.344-366.

Härtel, C.E., Gough, H. and Härtel, G.F. (2008) 'Work-group emotional climate, emotion management skills, and service attitudes and performance', Asia Pacific Journal of Human Resources, Vol. 46, No. 1, pp.21-37.

Hochschild, A. 1983. The managed heart. Berkeley: University of California Press.

Hobfoll, S. E. (1989) 'Conservation of resources: A new attempt at conceptualizing stress', American Psychologist, Vol. 44, No. 3, pp. 513-524.

Hui-Hua, Z and Schutte, N. S. (2015) 'Personality, emotional intelligence and other-rated task performance', Personality and Individual Differences, Vol. 87, pp. 298-301.

Johnson, H.A.M. and Spector, P.E. (2007) 'Service with a smile: Do emotional intelligence, gender, and autonomy moderate the emotional labor process?', Journal of Occupational Health Psychology, Vol. 12, No. 4, pp. 319-333

Jung, H. S. and Yoon, H. H. (2012) 'The effects of emotional intelligence on counterproductive work behaviors and organizational citizen behaviors among food and beverage employees in a deluxe hotel', International Journal of Hospitality Management, Vol. 31, No. 2, pp. 369-378. 
Karatepe, O.M. and Olugbade, O.A. (2009) 'The effects of job and personal resources on hotel employees' work engagement', International Journal of Hospitality Management, Vol. 28, No. 4, pp.504-512.

Karambayya, R. (1990) 'Contexts for organizational citizenship behavior: Do high performing and satisfying units have better citizens', Unpublished Paper, York University, Ontario.

Kearney, T., Walsh, G., Barnett, W., Gong, T., Schwabe, M. and Ifie, K. (2017) 'Emotional intelligence in front-line/back-office employee relationships', Journal of Services Marketing, Vol. 31, No. 2, pp.185-199.

Khalili, A. (2017) 'Transformational leadership and organizational citizenship behavior: The moderating role of emotional intelligence', Leadership \& Organization Development Journal, Vol. 38, No. 7, pp. 1004-1015.

Kulik, C.T., Cregan, C., Metz, I. and Brown, M. (2009) 'HR managers as toxin handlers: The buffering effect of formalizing toxin handling responsibilities', Human Resource Management, Vol. 48, No. 5, pp.695-716.

Kumari, P. and Thapliyal, S. (2017) 'Studying the Impact of Organizational Citizenship Behavior on Organizational Effectiveness', Human Resource Management, Vol. 4, No. 1, pp. $9-21$.

Koman, E.S. and Wolff, S.B. (2008) 'Emotional intelligence competencies in the team and team leader', The Journal of Management Development, Vol. 27, No. 1, pp. 55-75. 
Lee, J.J. and Ok, C. (2012) 'Reducing burnout and enhancing job satisfaction: Critical role of hotel employees' emotional intelligence and emotional labor', International Journal of Hospitality Management, Vol. 31, No. 4, pp.1101-1112.

Lopes, P.N., Salovey, P. and Straus, R. (2003) 'Emotional intelligence, personality, and the perceived quality of social relationships', Personality and Individual Differences, Vol. 35, No. 3, pp.641-658.

Ma, E., Qu, H. and Wilson, M. (2016) 'The affective and dispositional consequences of organizational citizenship behavior: A cross-cultural study', Journal of Hospitality \& Tourism Research, Vol. 40, No. 4, pp.399-431.

Ma, E., Qu, H., Wilson, M. and Eastman, K. (2013) ‘Modeling OCB for hotels: Don’t forget the customers', Cornell Hospitality Quarterly, Vol. 54 No. 3, pp.308-317.

Mayer, J.D., Salovey, P. and Caruso, D.R. (2008) 'Emotional intelligence: new ability or eclectic traits?', American psychologist, Vol. 63, No. 6, pp. 503-517.

Mayer, J. d., Caruso, d. R. and Salovey, P. (2000) 'Selecting a measure of emotional intelligence: the case for ability scales', In R. Bar-On \& J. D. A. Parker (Eds.), The handbook of emotional intelligence. New York: Jossey-Bass. Pp. 320-342.

Mayer, J.D., Caruso, D.R. and Salovey, P. (1999) 'Emotional intelligence meets traditional standards for an intelligence', Intelligence, Vol. 27, No. 4, pp. 267-298.

Miao, C., Humphrey, R.H. and Qian, S. (2017) 'A meta-analysis of emotional intelligence and work attitudes', Journal of Occupational and Organizational Psychology, Vol. 90, No. 2, pp. 177-202.

Miao, C., Humphrey, R.H. and Qian, S. (2016) 'Leader emotional intelligence and subordinate job satisfaction: A meta-analysis of main, mediator, and moderator effects', Personality and Individual Differences, Vol. 102, pp.13-24. 
Moorman, R.H., Blakely, G.L. and Niehoff, B.P. (1998) 'Does perceived organizational support mediate the relationship between procedural justice and organizational citizenship behavior?', Academy of Management Journal, Vol. 41, No. 3, pp.351-357.

McNelly, B.L. and Meglino, B.M. (1994) 'The role of dispositional and situational antecedents in prosocial organizational behavior', Journal of Applied Psychology, Vol. 76, No. 6, pp.836-844.

Mustafa, M., Santos, A. and Chern, G.T. (2016) 'Emotional intelligence as a moderator in the emotional labour-burnout relationship: evidence from Malaysian HR professionals', International Journal of Work Organisation and Emotion, Vol. 7, No. 2, pp. 143-164.

Nadiri, H. and Tanova, C. (2010) 'An investigation of the role of justice in turnover intentions, job satisfaction, and organizational citizenship behavior in hospitality industry', International journal of hospitality management, Vol. 29, No. 1, pp. 33-41. Narangajavana, Y. and Hu, B. (2008) 'The relationship between the hotel rating system, service quality improvement, and hotel performance changes: A canonical analysis of hotels in Thailand', Journal of quality assurance in hospitality \& tourism, Vol. 9, No. 1, pp. 34-56. Ninemeier, J. and Perdue, J. (2007). Introduction to hospitality (2nd ed.). Upper Saddle River, NJ: Prentice-Hall.

Organ, d. W., Podsakoff, P. M. and MaCkenzie, S.B. (2006) 'Organizational citizenship behavior: its nature, antecedents, and consequences', thousand oaks, ca: Sage Organ, D. W. (1988). Organizational citizenship behavior: The good soldier syndrome. Lexington, MA: Lexington Books.

Organ, D.W. and Konovsky, M. (1989) 'Cognitive versus affective determinants of organizational citizenship behavior', Journal of applied psychology, Vol. 74, No.1, pp. 157164. 
Ozer, D.J. and Benet-Martinez, V. (2006) 'Personality and the prediction of consequential outcomes', Annual Review of Psychology, Vol. 57, No. 4, pp. 401-421.

Podsakoff, N. P., Whiting, S. W., Podsakoff, P. M. and Blume, B. D. (2009) 'Individual- and organizational-level consequences of organizational citizenship behaviors: A meta-analysis', Journal of Applied Psychology, Vol. 94, No. 1, pp. 122-141.

Podsakoff, P.M., MacKenzie, S.B., Lee, J.Y. and Podsakoff, N.P. (2003) 'Common method biases in behavioral research: a critical review of the literature and recommended remedies', Journal of Applied Psychology, Vol. 88, No. 5, pp. 879-903.

Podsakoff, P.M., MacKenzie, S.B., Paine, J.B. and Bachrach, D.G. (2000) ‘Organizational citizenship behaviors: A critical review of the theoretical and empirical literature and suggestions for future research', Journal of Management, Vol. 26, No. 3, pp.513-563. Ramachandran, Y., Jordan, P.J., Troth, A.C. and Lawrence, S.A. (2011) 'Emotional intelligence, emotional labour and organisational citizenship behaviour in service environments', International Journal of Work Organisation and Emotion, Vol. 4 No. 2, pp.136-157.

Salovey, P. and Grewal, D. (2005) ‘The science of emotional intelligence’, Current Directions in Psychological Science, Vol. 14, No. 6, pp.281-285.

Santos, A., Mustafa, M.J. and Gwi, T.C. (2015) 'Trait emotional intelligence, emotional labour, and burnout among Malaysian HR professionals', Management Research Review, Vol. 38 No. 1, pp.67-88.

Scott-Halsell, S.A., Blum, S.C. and Huffman, L. (2008) 'A study of emotional intelligence levels in hospitality industry professionals', Journal of Human Resources in Hospitality \& Tourism, Vol. 7, No. 2, pp. 135-152. 
Spector, P. E. and Fox, S. (2002) 'An emotion-centered model of voluntary work behavior: Some parallels between counterproductive work behavior and organizational citizenship behavior', Human Resource Management Review, Vol. 12, No. 2, pp. 269-292.

Stamper, C.L. and Van Dyne, L. (2003) 'Organizational citizenship: A comparison between part-time and full-time service employees', The Cornell Hotel and Restaurant Administration Quarterly, Vol. 44, No. 1, pp. 33-42.

Suliman, A. M. and Al-Shaikh, F. N. (2007) 'Emotional intelligence at work: Links to conflict and innovation', Employee Relations, Vol. 29, No. 2, pp. 208-220

Tett, R.P. and Guterman, H.A. (2000) 'Situation trait relevance, trait expression, and crosssituational consistency: Testing a principle of trait activation', Journal of Research in Personality, Vol. 34, No. 4, pp. 397-423.

Turnipseed, D.L. (2016) 'January. Emotional Intelligence and OCB: The Moderating Role of Locus of Control', Academy of Management Proceedings', Vol. 20, No. 1, pp. 29-70.

Turnipseed, D.L. and Vandewaa, E.A. (2012) 'Relationship between emotional intelligence and organizational citizenship behavior', Psychological reports, Vol. 110, No. 3, pp. 899914.

Turnipseed, D.L. (2003) 'Hardy personality: a potential link with organizational citizenship behavior', Psychological Reports, Vol. 93, No. 2, pp. 529-543.

Van Dyne, L. and LePine, J.A. (1998) 'Helping and voice extra-role behaviors: Evidence of construct and predictive validity', Academy of Management Journal, Vol. 41, No. 1, pp. 108119.

Van Rooy, D. L. and Viswesvaran, C. (2004) 'Emotional intelligence: A meta-analytic investigation of predictive validity and nomological net', Journal of Vocational Behavior, Vol 65, No. 2, pp. 71-95.

Walter, F., Cole, M. S. and Humphrey, R. H. (2011) 'Emotional intelligence: Sine qua non of 
leadership or folderol?', Academy of Management Perspectives, Vol. 25, No. 1, pp. 45-59. Weinberger, L.A. (2003) 'An examination of the relationship between emotional intelligence, leadership style and perceived leadership effectiveness', (Doctoral dissertation, University of Minnesota).

Wong, C.S. and Law, K.S. (2002) 'The effects of leader and follower emotional intelligence on performance and attitude: An exploratory study', The Leadership Quarterly, Vol. 13, No. 3, pp. 243-274.

Woods, S. A., Mustafa, M. J., Anderson, N. and Sayer, B. (2017) 'Innovative work behavior and personality traits: Examining the moderating effects of organizational tenure' Journal of Managerial Psychology. 
Table 1: Means, standard deviations, intercorrelations and reliability coefficients

\begin{tabular}{|c|c|c|c|c|c|c|c|c|c|c|c|c|c|}
\hline & $\mathrm{M}$ & SD & 1 & 2 & 3 & 4 & 5 & 6 & 7 & 8 & 9 & 10 & 11 \\
\hline 1Gender & 1.50 & .50 & 1.00 & & & & & & & & & & \\
\hline 2Age & 35.58 & 12.66 & .071 & 1.00 & & & & & & & & & \\
\hline 3Tenure & 8.32 & 8.20 & $-.151^{*}$ & $.649 * *$ & 1.00 & & & & & & & & \\
\hline 4EFCC & 4.08 & 1.18 & .004 & .146 & .138 & 1.00 & $(.80)$ & & & & & & \\
\hline 5SEA & 6.08 & .94 & .023 & .003 & -.090 & $-.237 * *$ & $=1.00$ & $(.74)$ & & & & & \\
\hline 6OEA & 5.47 & 1.06 & -.132 & $-.174 *$ & $-.163 *$ & -.038 & $.410 * *$ & 1.00 & $(.77)$ & & & & \\
\hline 7UOE & 6.32 & .71 & .115 & -.085 & -.098 & -.135 & $.431 * *$ & $.451 * *$ & 1.00 & $(.84$ & & & \\
\hline $8 \mathrm{ROE}$ & 5.86 & .98 & .011 & $-.218 * *$ & $-.218 * *$ & $-.148 *$ & $.321 * *$ & $.376^{* *}$ & $.469 * *$ & 1.00 & $(.93)$ & & \\
\hline 9OCB-C & 3.49 & .86 & $.194 * *$ & $-.148 *$ & $-.148 *$ & $-.309 * *$ & $.193 * *$ & $.287 * *$ & $.311 * *$ & $.214 * *$ & 1.00 & (.83) & \\
\hline $10 \mathrm{OCB}-\mathrm{O}$ & 3.57 & .97 & $.236 * *$ & $-.166^{*}$ & $-.233^{*}$ & $-.260 * *$ & $.197 * *$ & $.303 * *$ & $.327 * *$ & $.235^{* *}$ & $.903 * *$ & 1.00 & $(.82)$ \\
\hline 11OCB-P & 3.43 & .97 & .068 & -.102 & -.134 & $-.323 * *$ & $.231 * *$ & $.303 * *$ & $.299 * *$ & $.178 *$ & $.887 * *$ & $.758 * *$ & 1.000 \\
\hline
\end{tabular}

Note. $N=179$. Reliability coefficients are stated in parenthesis. $\mathrm{FCC}=$ frequency of customer contact; SEA = self-emotion appraisal; OEA = others' emotion appraisal; $\mathrm{UOE}=$ use of emotion; $\mathrm{ROE}$ = regulation of emotion;

$* \mathrm{p}<.05, * * \mathrm{p}<.01$

Table 2: Direct and indirect effects of emotional intelligence and frequency of customer contact on OCB

\begin{tabular}{|c|c|c|c|c|c|c|c|c|c|}
\hline & \multicolumn{3}{|c|}{ OCB-C } & \multicolumn{3}{|c|}{ OCB-O } & \multicolumn{3}{|c|}{ OCB-P } \\
\hline Step 1 & $\boldsymbol{\beta}$ & $\mathbf{t}$ & Sig & $\boldsymbol{\beta}$ & $\mathbf{t}$ & Sig & $\beta$ & $\mathbf{t}$ & Sig \\
\hline Gender & .175 & 2.323 & .021 & .221 & 2.975 & .003 & .056 & 717 & ns \\
\hline Age & -.061 & -.623 & ns & -.090 & -.932 & ns & -.041 & -.409 & ns \\
\hline \multirow[t]{2}{*}{ Tenure } & -.153 & -1.550 & ns & -.141 & -1.443 & ns & -.098 & -.959 & ns \\
\hline & \multicolumn{3}{|c|}{$\mathrm{F}=4.837, \mathrm{p}=.003 ; \mathrm{R}^{2}=.077$} & \multicolumn{3}{|c|}{$\mathrm{F}=6.482, \mathrm{p}=.000 ; \mathrm{R}^{2}=.100$} & \multicolumn{3}{|c|}{$\mathrm{F}=1.244, \mathrm{~ns} ; \mathrm{R}^{2}=.021$} \\
\hline \multicolumn{10}{|l|}{ Step 2} \\
\hline SEA & -.051 & -.639 & ns & -.044 & -.553 & ns & -.011 & -.132 & ns \\
\hline OEA & .234 & 2.878 & .005 & .245 & 3.029 & .003 & .243 & 2.911 & .004 \\
\hline UOE & .155 & 1.844 & $\mathrm{~ns}$ & .156 & 1.875 & ns & .159 & 1.847 & ns \\
\hline ROE & .006 & .077 & ns & .023 & .300 & ns & -.035 & -.430 & ns \\
\hline \multirow[t]{2}{*}{ FCC } & .277 & 3.970 & .000 & .221 & 3.190 & .002 & .295 & 4.135 & .000 \\
\hline & \multicolumn{3}{|c|}{$\begin{array}{c}\mathrm{F}=7.161, \mathrm{p}=.000 \\
\Delta \mathrm{F}=7.977, \mathrm{p}=.000 \\
\mathrm{R}^{2}=.252, \Delta \mathrm{R}^{2}=.175\end{array}$} & \multicolumn{3}{|c|}{$\begin{array}{c}\mathrm{F}=7.566, \mathrm{p}=.000 \\
\Delta \mathrm{F}=7.495, \mathrm{p}=.000 \\
\mathrm{R}^{2}=.263, \Delta \mathrm{R}^{2}=.163\end{array}$} & \multicolumn{3}{|c|}{$\begin{array}{c}\mathrm{F}=5.867, \mathrm{p}=.000 \\
\Delta \mathrm{F}=8.484, \mathrm{p}=.000 \\
\mathrm{R}^{2}=.216, \Delta \mathrm{R}^{2}=.195\end{array}$} \\
\hline \multicolumn{10}{|l|}{ Step 3} \\
\hline SEA x FCC & -.202 & -1.298 & ns & -.270 & -1.740 & ns & -.162 & -1.004 & ns \\
\hline OEA x FCC & .495 & 3.389 & .001 & .457 & 3.139 & .002 & .396 & 2.611 & .010 \\
\hline UOE x FCC & .040 & .262 & ns & .140 & .911 & ns & .157 & .984 & ns \\
\hline \multirow[t]{2}{*}{ ROE x FCC } & -.324 & -2.108 & .036 & -.276 & -1.802 & ns & -.306 & -1.920 & ns \\
\hline & \multicolumn{3}{|c|}{$\begin{array}{c}\mathrm{F}=6.363, \mathrm{p}=.000 \\
\Delta \mathrm{F}=3.817, \mathrm{p}=.005 \\
\mathrm{R}^{2}=.315, \Delta \mathrm{R}^{2}=.063\end{array}$} & \multicolumn{3}{|c|}{$\begin{array}{c}\mathrm{F}=6.538, \mathrm{p}=.000 \\
\Delta \mathrm{F}=3.568, \mathrm{p}=.008 \\
\mathrm{R}^{2}=.321, \Delta \mathrm{R}^{2}=.058\end{array}$} & \multicolumn{3}{|c|}{$\begin{array}{c}\mathrm{F}=4.932, \mathrm{p}=.000 ; \\
\Delta \mathrm{F}=2.616, \mathrm{p}=.037 \\
\mathrm{R}^{2}=.263, \Delta \mathrm{R}^{2}=.046\end{array}$} \\
\hline
\end{tabular}

Figure 1: Buffering effect of OEA and customer contact on OCB-C 


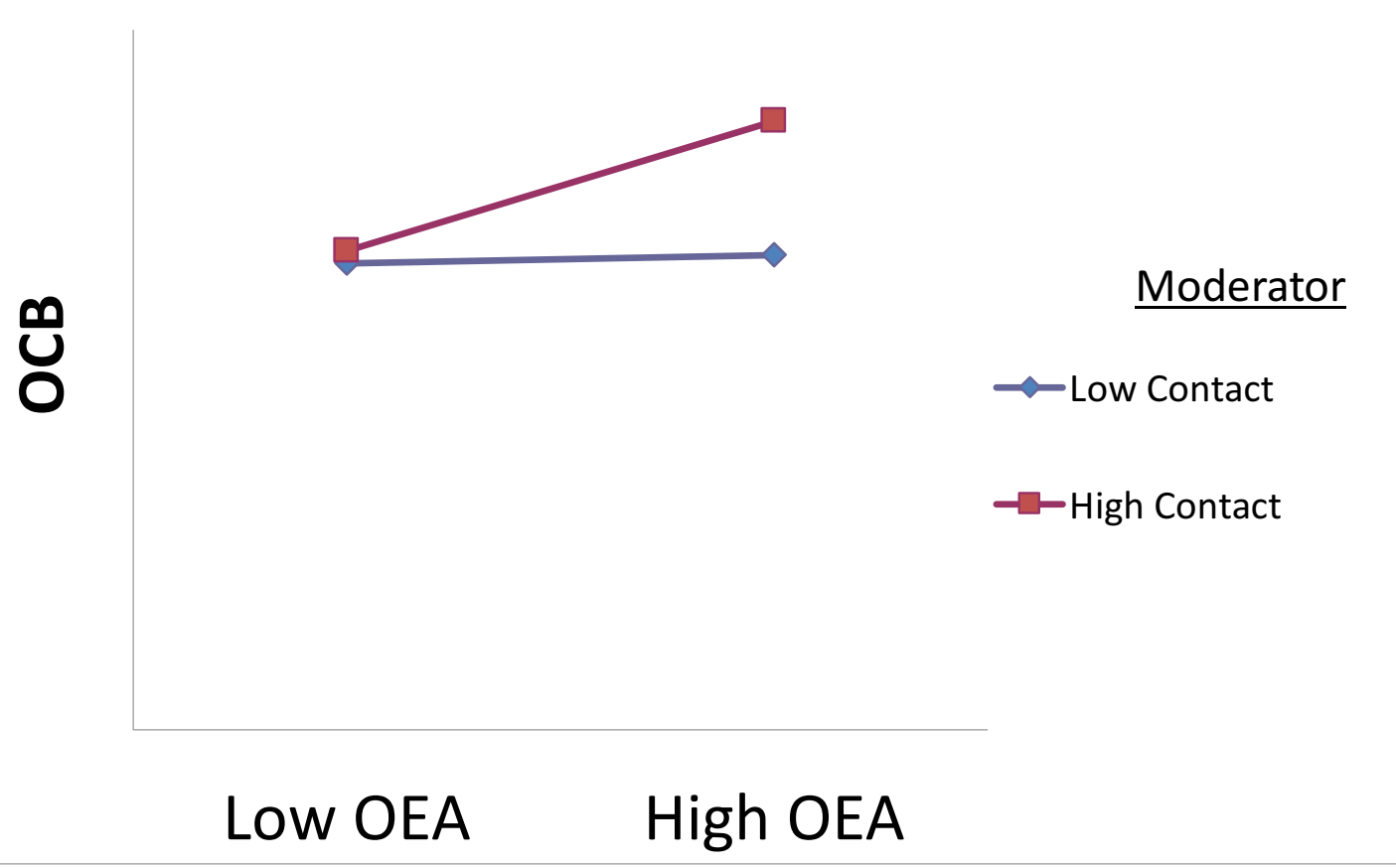

Figure 2: Reverse buffering effect of ROE and customer contact on OCB-C

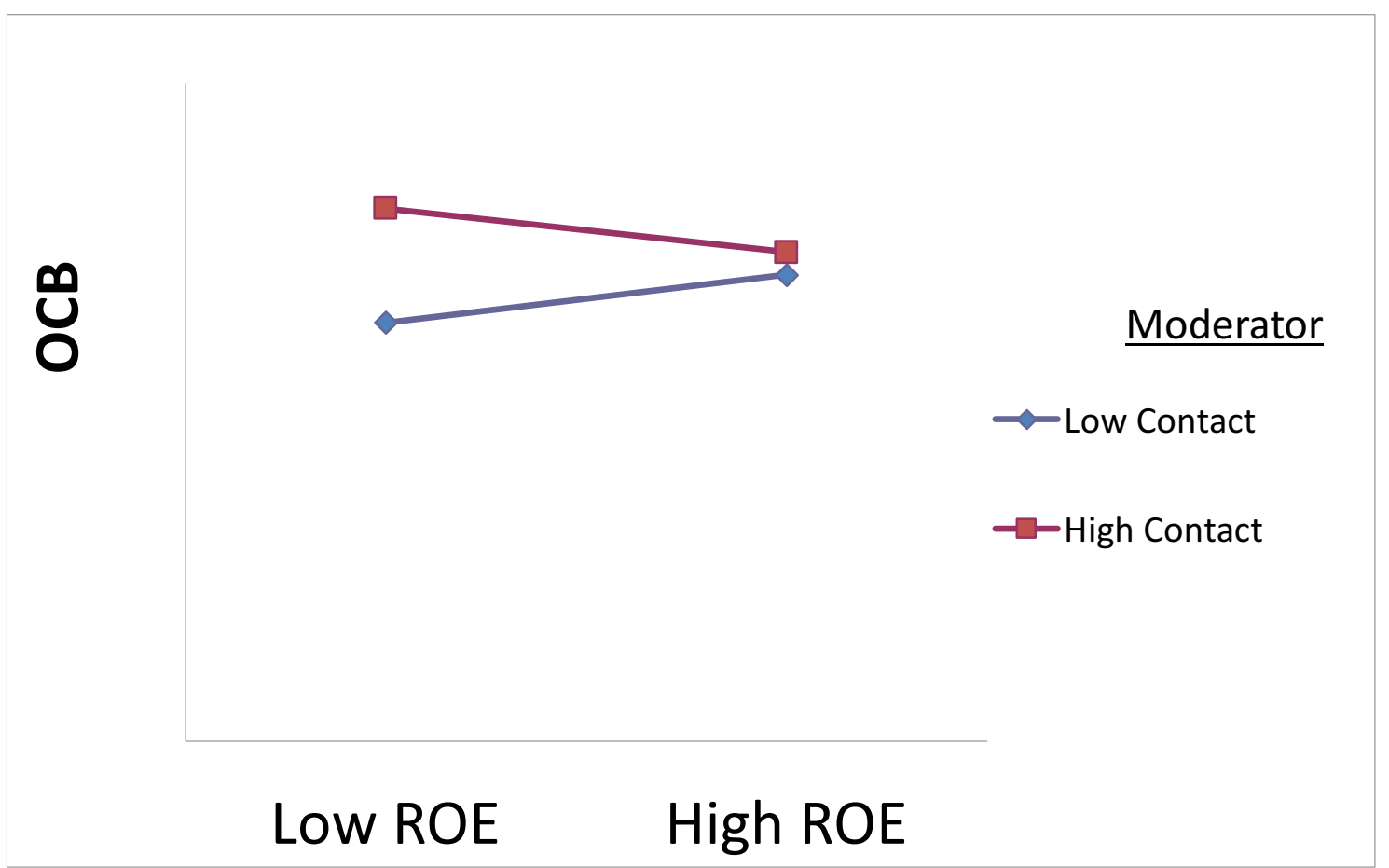

